\title{
Bearing Account-able Witness to the Ethical Algorithmic System
}

\section{Introduction}

This paper explores how accountability might make otherwise obscure and inaccessible algorithms available for governance. In popular discussions, algorithmic accountability is framed in terms of openness and transparency, at least theoretically enabling the algorithm, its authorship and consequences to be called to question by those subject to algorithmic decision-making processes (James 2013; Diakopoulos 2013). The potential importance of accountability is made clear across popular and academic reports, where we are told that algorithms trap us and control our lives (Spring 2011), produce new ways to undermine our privacy (Stalder and Mayer 2009) and have power, an independent agency to influence everyday activities. Hence, we are told that "algorithms have the capacity to shape social and cultural formations and impact directly on individual lives," (Beer 2009: 994), that "power is increasingly in the algorithm," (Lash 2007: 71), and that algorithms "acquire the status of truth...They become real." (Slavin 2011: n.p.). However, within these same discussions, accountability is made difficult by the apparent inaccessibility, complexity, obscurity, and intellectual property challenges posed by algorithms and the organisational settings within which they operate; as Slavin suggests: "We're writing things we can no longer read," (2011: n.p.).

Taken at face value these arguments contain an alluring and compelling drama. The new (in this case the development of algorithms to create distinct relations between digital data) is set up as a threat to the old (our ordinary ways of life) and the intensity of the drama is ratcheted up (not only are algorithms likely to change our lives, they are beyond our control, inaccessible, are working independently, and we cannot in principle understand them). The compelling drama is not solely focused on attributing definitive characteristics to algorithms. These are not just negative algorithms, they are also powerful and agential. They will act on us. With the emphasis of the compelling drama on the algorithm as inaccessible and out of control, what chance is there for accountability even as a prior step to governance?

One starting point for thinking through algorithmic accountability is provided by Science and Technology Studies (STS) research. The recent history of anti-essentialist or post-essentialist research (Rappert 2001) in STS warns us against attributing single, certain and fixed characteristics to things (and people). Furthermore, STS research on technologies, their development, claims to success and failure, and messiness and innovation also suggests that we ought to maintain a deep skepticism to claims regarding the agency or power of technology to operate alone. ${ }^{1}$ In STS work, the characteristics, agency, power and effect of technologies are often treated as the upshot of the network of relations within which a technology is positioned (Latour 1990; Law 1996). Rather than seeing agency or power as 
residing in the algorithm, as suggested by the compelling drama (above), this STS research can be used to raise questions about the set of relations that enable an algorithm to be brought into being. In place of seeing action or power as emanating from a single source, this approach encourages us to treat actions as emerging from complex and messy relations (Law 2004). ${ }^{2}$

Disturbing the notion that algorithms have fixed, essential characteristics and the claim that algorithms have power or agency deflates the compelling drama. In its place, we are presented with the possibility that algorithms might emerge from and operate in some more familiar sets of relations, like design and organizational work, perhaps even tied to budgets and priorities and strategic decisions. Algorithms might even be subject to some familiar forms of messiness. At the same time, if we take accountability to mean opening up algorithms to question, the deflationary sensibilities ${ }^{3}$ pose further challenges. If we try to move away from the idea that algorithms have fixed and certain characteristics, and a kind of predictable agential quality, we are faced with two difficult issues for algorithmic accountability. First, approaches to accountability can be focused on the production of a singular account of a technology (Woolgar and Neyland 2013); such an account would more or less fix in place the algorithms' characteristics. Second, attempts to render a technology accountable in terms of its future trajectory would also risk attributing a fixed and agential even deterministic - quality to the technology in focus ${ }^{4}$; such an account would risk attributing certainty and responsibility for such a future path to the algorithm (a kind of literal algorithmic accountability).

The deflationary sensibilities, then, are important for steering us away from taking for granted that algorithms might have a fixed, essential characteristic and might determine a single and predictable future. However, these sensibilities must be incorporated into an approach to accountability. This is the main task of the paper: to develop an approach to algorithmic accountability that can also take on the deflationary sensibilities. In the next section I will introduce the project on which this paper is based - an attempt to develop an "ethical" algorithmic surveillance system - and I will set out the approach to accountability that was developed. Then I will use empirical data from the project to work through some of the challenges of attempting algorithmic accountability in action. The conclusion will offer reflections on future questions of algorithms and accountability.

\section{The project: an ethical algorithmic system?}

The project upon which this paper is based began with an e-mail invitation: would I be interested in researching the development of a new "algorithmic," "smart" and "ethical" video-based surveillance system? The potential coordinator informed me that the project would involve a large technology firm $\left(\right.$ TechFirm $\left.{ }^{5}\right)$, two large transport firms where the technology would be tested and developed (SkyPort which owns and operates two large European city airports and StateTrack a large European state railway), two teams of computer scientists (from University 1, UK and University 2, Poland) and the project would be 
managed by a consultancy firm (Consultor, Spain). I was being invited to oversee the ethics of the technology under development ${ }^{6}$ and to provide an (at least partially ${ }^{7}$ ) independent ethical assessment.

The coordinator suggested the project would become an experimental location for exploring three ethical aims: that algorithms could be used to reduce the scope of data made visible within a video-based surveillance system; that algorithms could be used to automatically delete the vast majority (perhaps $95 \%$ ) of surveillance data; and that no new algorithms ${ }^{8}$ or surveillance networks would need to be developed to do so. These aims had been developed by the coordinator into an initial project bid, and the coordinator hoped their "ethical" qualities were clear in the way the aims were positioned in the bid as a response to issues raised in popular and academic discussions. ${ }^{9}$ In particular, the project bid set out to engage with contemporary concerns regarding data retention and deletion. ${ }^{10}$

The ethical aims provided one basis for holding the system to account, but developing the precise method for rendering the algorithmic system accountable was to be my responsibility. Traditional approaches to ethical assessment have included consequentialist ethics (whereby the consequences of a technology, for example, would be assessed) and deontological ethics (whereby a technology would be assessed in relation to a set of ethical principles; for a discussion, see Sandvig et al. 2013). However, these traditional approaches seemed to fit awkwardly with the deflationary STS sensibilities marked out at the beginning of the paper. To judge the consequences of the algorithm or to what extent an algorithm matched a set of deontological principles appeared to require the attribution of fixed characteristics and a fixed path of future development to the algorithm prior to its testing. ${ }^{11}$ As an alternative, I suggested to the potential project team that taking an ethnographic approach to algorithms and their ethics might have some utility for researching in detail an area of activity that was only just emerging as a potential field of social science research ${ }^{12}$ and one in which ethical principles and standards had yet to be developed. $\mathrm{We}^{13}$ moved toward discussing the possibility of an on-going ethnographic study of the ethical algorithm in action. I pointed project members toward ethnographic studies of ethics as an on-going accomplishment. ${ }^{14}$

Although the project team was happy to accept an ethnographic approach, I sought to avoid a method that would provide nothing more than a singular ethnographic snapshot of some algorithmic activity. Such an approach seemed likely to miss the detail of how an algorithm was designed or expected to work, the organizational relations within which it was positioned, how it changed over time and so on. I was concerned that a single ethnographic snapshot, through its lack of depth or brief timeframe, would also risk problematically fixing a set of essential characteristics and a single, future trajectory for the algorithm, and might also risk attributing such a trajectory to a kind of deterministic and agential algorithm. Instead, I turned to pre-project discussions for inspiration. It was clear in these discussions that algorithms were implicated in design, development and testing decisions involving a number of intersecting potential components, including video streaming, deletion and relevance-detection technologies (explored further in the next section). It seemed possible to use these as the basis not for developing a singular ethnographic snapshot of some algorithmic activities, but instead for engaging with the ways in which the algorithmic system 
was expected to, and went about the business of, making sense of particular spaces (in this project, a train station and an airport). Trying to make sense of the ways in which the algorithm was implicated in making sense seemed to provide a rich way forward. In order to further develop this line of thinking I turned to ethnomethodological studies of sense-making accounts.

\section{Ethnomethodology and the account-able}

To develop further a means to study the activities through which algorithms were involved in making sense of spaces such as airports and train stations, I looked to the ethnomethodogical use of the hyphenated version of the term: account-able (Garfinkel 1967; Eriksen 2002). ${ }^{15}$ Garfinkel suggests that "the activities whereby members produce and manage settings of organized everyday affairs are identical with members' procedures for making those settings 'account-able"' (1967: 1). For ethnomethodologists, this means that actions are observablereportable; their character derives from the ability of other competent members to assess and make sense of actions in a context. Importantly, making sense of actions involves the same methods as competently taking part in the action. To be account-able thus has a dual meaning of being demonstrably open to inspection as an account of some matter and being able to demonstrate competence in making sense of some matter (see Lynch 1993 and Dourish 2004 for more on this).

Although ethnomethodologists have studied the account-able character of everyday conversations, they have also developed a corpus of workplace studies (Heath and Button 2002). Here the emphasis is on the account-able character of, for example, keeping records, following instructions, justifying actions in relation to guidelines and informing others what to do and where to go (Lynch 1993: 15). For Button and Sharrock (1998) actions become organizationally accountable when they are done so that they can be seen to have been done on terms recognizable to other members within the setting as competent actions within that organization. Extending these ideas, studying the algorithm on such terms would involve studying the work of computer scientists and others involved in the project in order to make sense of the terms of account-ability within which the algorithm comes to participate in making sense of a particular scene placed under surveillance. This is not to imply that the algorithm operates alone. Instead I will suggest that an understanding of algorithmic account-ability can be developed by studying how the algorithmic system produces outputs that are designed to be used as part of organizational practices to make sense of a scene placed under surveillance by the algorithmic system. ${ }^{16}$ I will refer to these sense-making practices as the account-able order of the algorithmic system. Having algorithms participate in account-ability changes the terms of the account-able order (in comparison to the way sense was made of the space prior to the introduction of the algorithmic system).

Making sense of this account-able order may still appear to be some distance from the initial concerns with accountability which opened this paper, of algorithmic openness and transparency ${ }^{17}$; indeed the ethnomethodological approach appears to be characterized by a different register of account, with ethnomethodologists interested in moment to moment sense-making, while calls for algorithmic accountability are attuned to the perceived needs of those potentially subject to actions deriving from algorithms. However, Suchman et al. 
(2002) suggest that workplace actions, for example, can involve the simultaneous interrelation of efforts to hold each other responsible for the intelligibility of our actions (account-ability) while located within constituted "orders of accountability" (164). In this way the account-able and the accountable, as different registers of account, might intersect. As I will go on to suggest, demands for an algorithm to be accountable (in the sense of being transparent and open to question) might benefit from a detailed study of the account-able order of an algorithmic system under development. Being able to elucidate the terms of algorithmic participation in making sense of scenes placed under surveillance - as an account-able order - might assist in opening the algorithmic system to accountable questioning. However, for this to be realized requires practically managing the matter of intersecting different registers of account.

For the account-able to intersect with the accountable took some effort even before the project began. I proposed combining my ethnomethodologically-inflected ethnography of the algorithm's account-able order with a particular form of accountability - an ethics board to whom I would report and who could raise questions. ${ }^{18}$ The interactions through which the algorithm came to make sense of particular scenes - as an account-able order - could be presented to the ethics board so that they could raise questions - a form of algorithmic accountability. As the following sections will show, intersecting registers of accounts (account-ability and accountability) did not prove straightforward. The next section of the paper will detail efforts to engage with the account-able order of the algorithm in design and testing. The subsequent section will then explore the intersection of account registers through the ethics board. The paper will conclude with questions for future considerations of algorithms and accounts.

\section{Designing and testing an "ethical" algorithmic system}

The proposal was a success and the project was granted $€ 2.8 \mathrm{~m}$ (about $\$ 3.1 \mathrm{~m}$ in mid-2015) under the European Union's $7^{\text {th }}$ Framework Programme. The promises committed to the project bid (of ethical algorithms) would now have to be fulfilled.

In order to look in detail at the development of the algorithmic system through design ${ }^{19}$ and testing, the following analysis draws together data from algorithm tests, meetings among project members, telephone conversations, e-mail exchanges and the content of project documents. Accomplishing the ethical aims of the project - to reduce the scope of visibility and data storage of a video-surveillance system, without developing new algorithms involved four areas of design and testing work, which established the algorithmic system's initial (but as it turned out, precarious) account-able order.

First, much of the time in initial project meetings was devoted to discussions of algorithmic means to detect events. A set of algorithms and already-developed code/software existed for use on digital video surveillance equipment. Although Goffey (2008; see also Kraemer et al. 2011) suggests that an algorithm is nothing more than a basic set of instructions to be executed by computer code/software, and despite being continually discussed as "algorithms" 
by members of the project team, these were more or less fully developed software packages that, according to the computer scientists, could be "dropped into" existing surveillance architectures. ${ }^{20}$ These algorithms and code/software could sift through terabytes of visual digital data and select the few moments that might be deemed "relevant" for further scrutiny. ${ }^{21}$ The project coordinator delegated responsibility to the end users (SkyPort and StateTrack) to define a set of requirements that they would wish for in a surveillance system and thus to define what counted as "relevant." The two end users, together with the computer scientists in the project, selected three types of activity that they would initially like the system to detect algorithmically. ${ }^{22}$ These were entry into forbidden areas (intrusion), moving in the wrong direction (counter-flow), and abandoned luggage. Identifying these types of incidents was presented by operators as comprising an important part of what I will term their everyday competences in securing the airport and train station. ${ }^{23}$

These design decisions confirmed my initial skepticism regarding consequentialist or deontological ethics. It seemed difficult to judge whether, for example, using abandoned luggage as a basis for relevance detection would have a clear consequence or would adhere to a normative principle. I instead focused on producing a detailed study of the emerging account-able order of relevance-detection algorithms as a basis for possible future accountability work. The computer scientists established an initial scheme for how the three types of relevance detection would work. Algorithms and associated code would sift through video frames travelling through the system, which would use a media proxy to draw together the streams of video from cameras across a surveillance network using a Real-Time Streaming Protocol for MPEG4 using JSON (JavaScript Object Notification) as a data interchange format for system analysis. Each stream would have a metadata timestamp. The algorithms would select out object types (using a Codebook algorithm for object detection) focusing on their dimensions, direction and speed. The system would generate bounding boxes for objects that would then be given a metadata identity (based on dimension and timing, which will be discussed below). For the algorithms to work, the fixed attributes of end-user sites would be mapped so that any moving objects (human or non-human) could be identified by the system as proto-relevant objects. Areas where entry was forbidden for most people (for example, secure areas, train tracks, etc.) and areas where the direction of movement was sensitive (for example, exits at peak times in busy commuter train stations) would also be mapped. Relatively simple looking algorithms in the form of "IF-THEN" rules would then be instated to monitor these spaces (for example, IF an object crosses a line digitally imposed on a space, THEN an "intrusion" alert will be sent to system operators).

For abandoned luggage (Figure 1), the disaggregation of a pixel-based bounding box of person+thing would lead to the implementation of a more complex "IF-THEN" rule. With abandoned luggage, IF the person and thing disaggregated, one part of the disaggregated bounding box then failed to move, the two entities were at least a certain distance apart (say 2 or 10 metres) and remained apart for a certain amount of time (say 10 or 60 seconds), THEN an alert would be sent to operators. The metadata added to the alert image would include the timestamp, camera location, dimensions, direction and speed of the object. 
The "IF-THEN" rules provided the algorithmic basis for relevance detection. The development of "IF-THEN" rules, and the decision to focus on 3 areas of relevance detection, also provided an initial insight into the account-able order of the algorithmic system. In the immediate project setting, the order emerged through collaborative decision making between computer scientists from Universities 1 and 2, networking experts from TechFirm and representatives from StateTrack and SkyPort. Collaborative work also invoked a future account-able order of airport and train station interactions between the operators of the system and passengers and their luggage. The future everyday competences of the system operators involved in securing the space of the train station and airport were opened for discussion around the "IF-THEN" rules. The rules provided a basis for discussing future occasions where operators would be provided with data on which decisions would be made regarding, for example, suspicion.

Figure 1: A suspicious item of luggage:

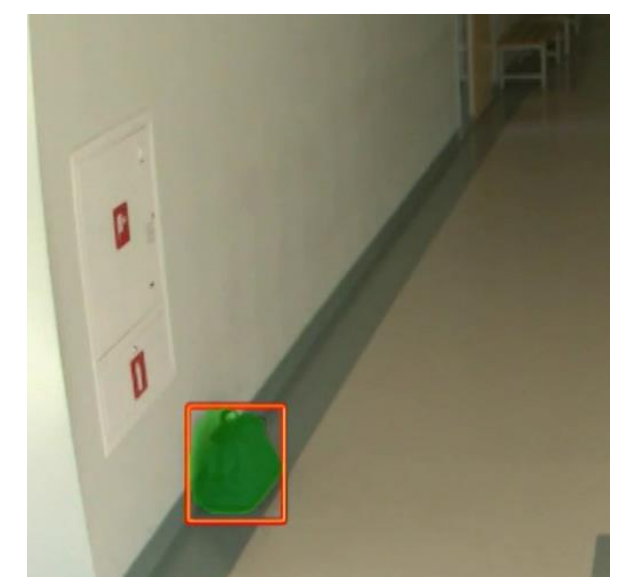

However, the "IF-THEN" rules were only a starting point for thinking through account-ability. Second, given that an ethical aim of the project was to reduce the scope of data made visible, the computer scientists tried to work through with the end users how little a surveillance system operator needed to see for the system still to be considered functional. In this way, the ethical aims of the project began to form part of the account-able order of the algorithmic system. Hence, decision making could be demonstrably organized so that it could be seen to match the aims at the same time as the emerging system could be constituted as a particular material-algorithmic instantiation of the aims. For example, a decision to move forward with developing an operator interface with no general visual component was both made to make sense as a demonstrable, account-able response to the ethical aims (to reduce visibility) and constituted a visually and materially available form for the otherwise somewhat general aims. In place of the standard video-surveillance bank of monitors continually displaying images, operators would be presented only with text alerts (Figure 2) produced by the algorithmic "IF-THEN" rules. Operators would then be given the opportunity to click on a text alert and a short video of several seconds that had created the alert would appear on the operator's screen. The operator would then have the option of deciding whether the images did indeed portray an event worthy of further scrutiny or could be ignored. Operators could then tag data as relevant or irrelevant. 


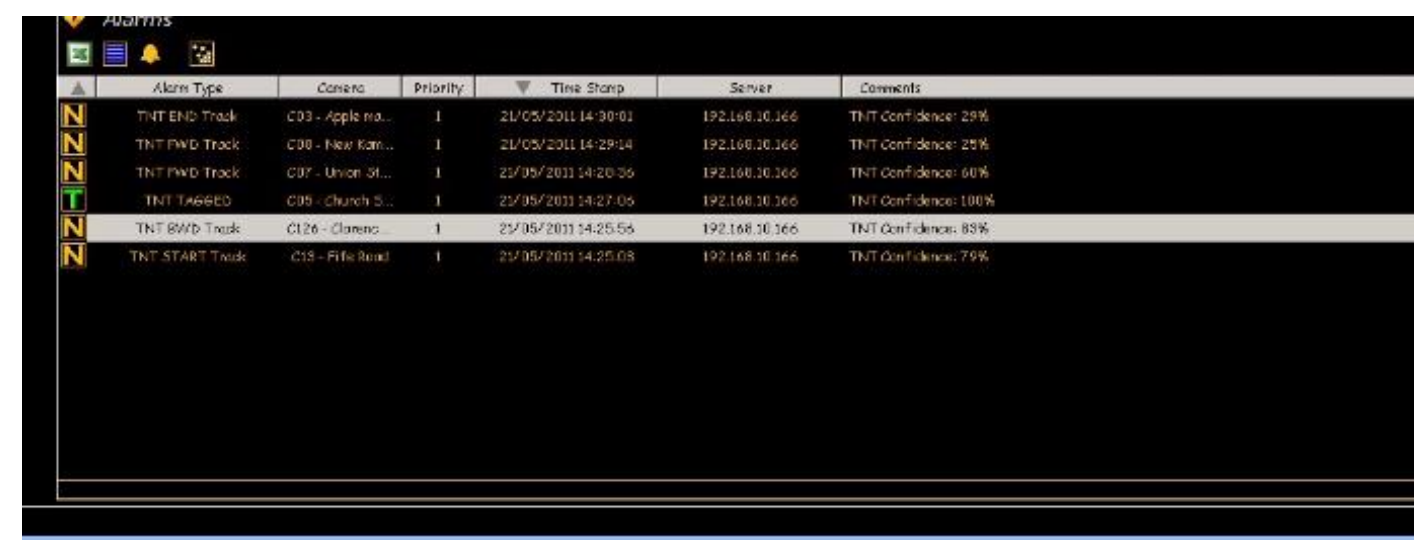

The "IF-THEN" rules and the text-based alert system would thus decide what was rendered visible (relevant) and invisible (irrelevant) to operators. Except that the operators and their managers now complained: how could they maintain security if all they got to see was (for example) an image of an abandoned item of luggage; to secure the airport or train station they needed to know who had abandoned the luggage, when and where did they go? As such, the emerging account-able order of the algorithmic system and the design decisions, which acted as both a response and gave form to the project's ethical aims, were subject to ongoing development, particularly in relation to operators' everyday competences. Hence a third area of design decision making emerged around the questions posed by operators and their managers of how they could make sense of an image of abandoned luggage. This discussion was directed toward reconstructing a focused history around an event. The University 1 team of computer scientists presented a digital surveillance route reconstruction system they had been working on (using a learning algorithm to generate probabilistic routes). Any person or object once tagged relevant, they suggested, could be followed backwards through the stream of video data (for example, where had a bag come from prior to being abandoned, which human had held the bag, etc.) and forwards (for example, once someone had dropped a bag, where did they go next).

Route reconstruction would work by using maps of fixed attributes in end user sites to establish a database of popular routes and the average time it took someone to walk from one camera to another. The system would also use the bounding boxes placed around (human and non-human) objects deemed relevant to note their dimensions, direction and speed. The route reconstruction system would then sift through the digital stream of video images using algorithms to locate, for example, a person who had been subject to an alert and trace the route from which they were most likely to have arrived (using the database of most popular routes), how long it should have taken them to appear on a previous camera (based on their speed) and search for anyone that matched their bounding box dimensions. If unsuccessful, the system would continue to search other potential routes and sift through possible matches to send to the operators, who could then tag those images as also relevant or irrelevant. The idea was to create what the computer scientists termed a small "sausage" of data from among 
the mass of digital images. The route reconstruction system used probabilistic trees (Figure 3), which took an initial image (of, for example, an abandoned item of luggage) and then presented possible "children" of that image (based on dimensions, speed and most popular routes) until operators were happy that they had established the route of the person and/or object in question.

Figure 3: A probabilistic tree and children (BO and $\mathrm{FO}$ are the same image):

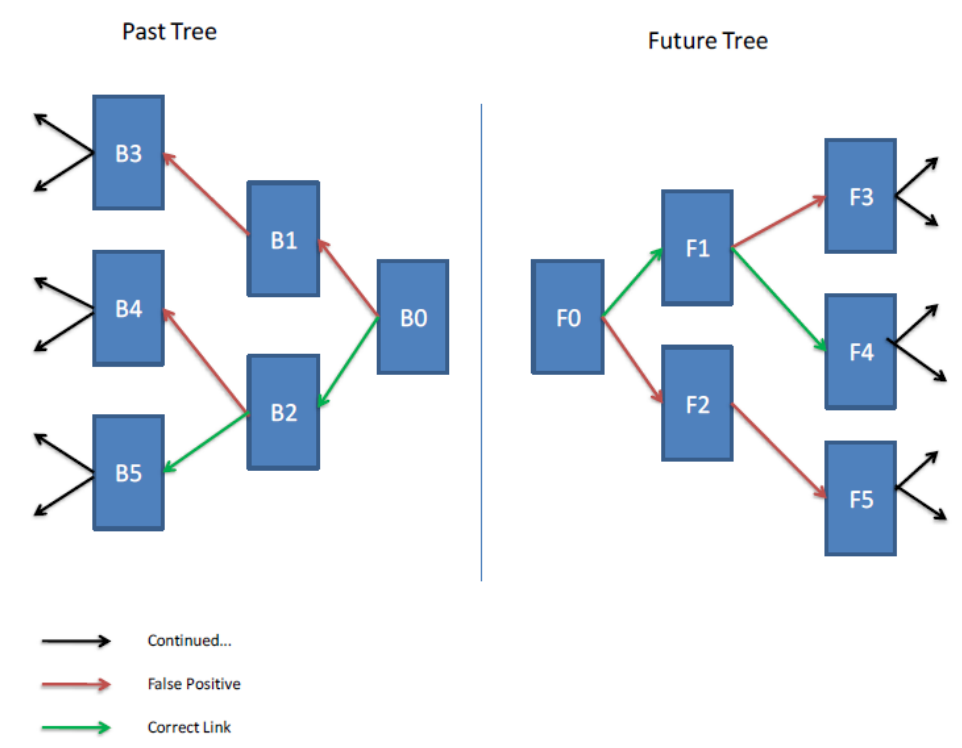

As a result of end users' articulation of a potential clash between an ethical aim of the project (to reduce visibility) and the everyday competences of surveillance operators (to secure a train station or airport space through comprehensive visibility), the account-able order of work between computer scientists, end users, their working practices, user interfaces and so on shifted somewhat to incorporate route reconstruction. Route reconstruction became a basis for account-ably acknowledging the existing competences of operators in securing a space. The small "sausages" of data and probabilistic "children" became a means of broadening the number of account-able entities. Having "sausages" of data and new forms of metadata (used to produce "children") might initially appear to move the project away from its stated ethical aim to reduce amounts of surveillance data made visible. However, simultaneous to these emerging design changes, a fourth area of design decision making was oriented toward the deletion of data.

Computer scientists from Universities 1 and 2 spent some time in meetings taking project members through conventions for deletion. Most forms of deletion, it turned out, either left a trace of the original from which data might be extracted or simply changed the route through which a user might connect to data. To provide a more thorough form of deletion, a decision was taken by the project coordinator to use solid state drives for data storage and then build an auto-deletion system to overwrite this data. In order to orient deletion as a means of account-ably demonstrating adherence to the project's ethical aim to reduce surveillance data, the system under development would need to be able to delete "irrelevant" data, data which had been tagged "relevant" once it was no longer needed and metadata (such as timestamps 
and bounding box dimensions). Discussions around deletion continued in project meetings: how quickly should data be deleted and how could it be shown that deletion had taken place? Having studied data protection law in the various member states participating in the project, I suggested that in accordance with Italian data protection principles, all irrelevant data and metadata should be deleted every 24 hours. Project members from TechFirm also discussed designing an automated logging system that could provide regular evidence (to Data Protection Officers, for example) that data was being thoroughly and securely deleted. In this way, the speed of deletion, its thoroughness and the ways it would be reported could each be made to make sense in relation to project ethical aims.

At this point (at least for a time) it seemed that I was in a position to produce a detailed presentation of the account-able order of the algorithmic system that would avoid an overly simplified snapshot. In place of a static snapshot of the system was an account of an emerging order in which terabytes of visual, video data would be sifted by relevance detection algorithms, using background subtraction models to select out proto-relevant human and non-human objects and actions. Operators would then have the responsibility to decide on future courses of action as a result of the alerts they were sent (for example, alerting airport security staff to items of luggage). The alerts were the first means through which the algorithmic system could participate in the account-able order of the scene placed under surveillance. Subsequent operator responses could also shift responsibility for a second form of account-able action back onto the algorithmic system if route reconstruction were deemed necessary, with probabilistic trees and children designed to offer images of protopast and subsequent actions (once again to be deemed relevant by operators). The deletion system would then participate in a third form of action, overwriting all data deemed irrelevant every 24 hours and producing a log detailing the system's success in achieving this task. Through this account-able order the algorithmic system was involved in making sense of particular spaces, such as an airport or train station, and held out the possibility of contributing to changes in operators' everyday competences in securing those spaces. The presence of the algorithmic system proposed notable changes in the operators' activities. Instead of engaging with large amounts of video data in order to make decisions, operators would only be presented with a small amount of data to which their responses were also limited. Conversely, for the algorithmic system to work, much greater amounts of data were required prior to the system operating (for example, digitally mapping the fixed attributes of a setting such as an airport and fixing in place parameters for objects such as luggage and humans). The introduction of the algorithmic system seemed to require a much more precise definition of the account-able order of airport and train station surveillance activities. The form that the order took was both oriented to the project's ethical aims and gave a specific form to those aims.

The specific material forms that were given to the project's ethical aims - such as the user interface and deletion system - were beginning to intersect with accountability questions being raised by the ethics board. In the next section I will explore the challenges involved in this intersection of distinct registers of account by engaging with the work of the ethics board. 


\section{Intersections of account-ability and accountability and the "ethical" algorithmic system}

The ethics board became a key means for the account-able order of the algorithmic surveillance system and the accountable questions posed of algorithms, to intersect. The ethics board comprised a Member of the European Parliament (MEP) working on redrafting the EU Data Protection Regulation, two national Data Protection Authorities (DPAs), two privacy academics and two members of privacy-focused civil liberty groups. The ethics board met three times during the course of the project and during these meetings I presented my developing study of the account-able order of the algorithmic system. ${ }^{24}$ I presented the ways in which the algorithmic system was involved in making sense of spaces like an airport and a train station, how it was expected to work with operators' everyday competences for securing those spaces and how the system gave form to the project's ethical aims. In place of buying into the claims made on behalf of algorithms by other members of the project team or in popular and academic discussions of algorithms, I could present the account-able order as a more or less enduring, but also at times precarious focus for action. In response, members of the ethics board used my presentations along with demonstrations of the technology to open up the algorithmic system to a form of accountability by raising questions to be included in public project reports and fed back into the ongoing project.

Ethics board members drew on my presentations of the account-able order of the algorithmic system to orient their questions. In the first ethics board meeting (held approximately ten months into the project) one of the privacy-focused academics pointed to the centrality of my presentation for their considerations:

From a social scientist perspective it is not enough to have just an abstract account for ethical consideration. A closer understanding can be brought about by [my presentation's] further insight into how [the system] will work.

The way the system "will work" - its means of making sense of the space of the airport and train station - encouraged a number of questions from the ethics board, enabling the system to be held accountable. For example, the Data Protection Officers involved in the board asked during the first meeting:

"Is there a lot of prior data needed for this system? More so than before?"

"Are people profiled with in the system?"

"How long will the system hold someone's features as identifiable to them as a tagged suspect?"

These questions drew attention to matters of concern that could be taken back to the project team and publicly reported (in the minutes of the ethics board) and subsequently formed the basis for response and further discussion at the second ethics board meeting. The questions could provide a set of terms for making the algorithmic system accountable through being made available (in public reports) for broader consideration. The questions could also be made part of the account-able order of the algorithmic system, with design decisions taken on 
the basis of questions raised. In this way the computer scientists could ensure that there was no mechanism for loading prior data into the system (such as a person's dimensions, which might lead to them being tracked), and to ensure that metadata (such as the dimensions of human-sized objects) were deleted along with video data to stop individual profiles being created or to stop "suspects" from being tagged. Data Protection Officers sought to "use the committee meetings to clearly shape the project to these serious considerations." The "serious considerations" here were the ethical aims. One of the representatives of the civil liberties groups also sought to utilize the access offered by the ethics board meetings but in a different way, noting that "As systems become more invisible it becomes more difficult to find legitimate forms of resistance."

To "shape the project" and "find legitimate forms of resistance" through the project seemed to confirm the utility of intersecting account-ability and accountability; opening up distinct ways for the system to be questioned and for that questioning to be communicated to further interested audiences. However, as the project progressed, there were two types of issue that complicated my presentation of the account-able order of the algorithmic system to the ethics board and hence made the intersection of account-ability and accountability more difficult.

First, I reported to the ethics board a series of issues involved in system development. For example, I presented to the ethics board the challenges involved in "dropping in" existing algorithms. Although one of the project's opening ethical aims was that no new algorithms would be developed and that existing algorithms could be "dropped into" existing surveillance networks, these were also termed "learning" algorithms. I presented to the ethics board an acknowledgement from both teams of computer scientists that the algorithms needed to "learn" to operate in the end user settings; that algorithms for event detection and route reconstruction had to run through streams of video data; that problems in detecting objects and movements had to be continually reviewed; and that this took " 10 s of hours." When problems arose in relation to the lighting in some areas of end-user sites (where, for example, the glare from shiny airport floors appeared to baffle left luggage algorithms which kept constituting the glare as abandoned luggage), the code/software tied to the eventdetection algorithm had to be developed - this I suggested to the ethics board is what constituted "learning."

These ongoing changes to the system through "learning" emphasized the complexities of making sense of the algorithmic system's account-able order; the way the system went about making sense changed frequently at times and my reporting to the ethics board needed to manage and incorporate these changes. Alongside the continual development of "learning" algorithms, other issues that emerged as the system developed included an initial phase of testing where none of the system components would interact. In this instance it turned out that one of the project members was using obsolete protocols (based on VAPIX), which other project members could not use or did not want to use. Attempting to resolve this issue took 114 e-mails and four lengthy telephone conference calls in one month of the project. ${ }^{25}$ Other issues that emerged included: questions of data quality, frame rates, trade union concerns, pixilation and compression of video streams, which each led to changes in the ways in which the system would work. In particularly frenzied periods of project activity I found it more 
challenging to maintain a clear notion of what constituted the "order" of the algorithmic system to report to the ethics board, as major features (for example, which components of the system talked to each other) would be changed in quite fundamental ways. When the route reconstruction and deletion components of the system were also brought together with the event-detection algorithms, reporting became more difficult again.

The ongoing changes of system development emphasized the value of steering away from producing a singular ethnographic snapshot of algorithmic activity and toward building an understanding of the system's developing account-able order. Making sense of the way in which the system (its components, design decisions, designers, software, instructions and so on) was involved in making sense of end user spaces, avoided providing a more or less certain account developed from a single or brief timeframe that simply captured and replayed moments of system activity, as if the system had a singular, essential characteristic. Instead, understanding the account-able order held out the promise of making sense of the ordering practices of the system under development.

Tracing system developments and the changing account-able order of the algorithmic system for presentation to the ethics board also became the principal means of intersecting the different registers of account-ability and accountability. In place of presenting a static picture of the algorithmic system, changes in the ordering activities of the system could be demonstrated and discussed in relation to the project's ethical aims. This was particularly important in ethics board meetings as changes that emerged through system development appeared to change the specific form given to the project's ethical aims. For example, as the project developed, a question for the ethics board was how far could an algorithm "learn" and be changed before it was considered sufficiently "new" to challenge the ethical aim of the project to not introduce new algorithms? ${ }^{26}$ This intersection of account-ability and accountability was not resolved in any particular moment, but became a focal point for my ethics board presentations and ensuing discussions and public reporting.

Alongside system development, a second issue that became a focus for discussion in ethics board meetings was the complexity of my own role in this intersection of account-ability and accountability. In the first ethics board meeting, although I was interested in making sense of the account-able order of the algorithmic system, I felt more comfortable providing a partial (Strathern 2004) and modest (Haraway 1997) account. My developing understanding of the system was entangled with the computer scientists and other project members' development of the system; there was no view from nowhere (Haraway 1997), and no complete account of the system. However, members of the ethics board responded that they expected something akin to an expert view (see Cole 2009; Lynch et al. 2008) from me, not just on the technical features of the system, but also of the extent to which the system was achieving its ethical aims.

As the project and ethics board meetings progressed, my role in producing accounts became more difficult. I was involved in making available an analysis of the account-able order of the system partly as a means to open the system to questions of accountability, which I would then publicly report and feed back to project members. At the same time, I was not just 
creating an intersection between account-ability and accountability, I risked being deeply involved in producing versions of the system's account-able order which might steer ethics board members toward recognizing that the system had achieved or failed to achieve its ethical aims and thus defuse or exacerbate accountability concerns. As one of the Data Protection Officers on the ethics board asked, "What is the [author of this paper's] role? How can he ensure he remains impartial?"

Rather than try to resolve this problem in a single ethics board meeting, I sought instead to turn this issue of my own accountability into a productive tension by bringing as much as possible to the ethics board. My own partial, modest and developing account of the account-able order of the algorithmic system, the computer scientists, end users, the technology as it developed and the reports the system itself produced (for example, the deletion logs) could all be drawn together in ethics board meetings. The result was not a single, agreed upon expert view on the system. In place of a single witnessed account, the meetings became moments for different views, evidence, material practices and so on to be worked through. The effect was to intersect account-ability and accountability through what I came to consider as a form of distributed witnessing. ${ }^{27}$ Questions and attributions of algorithmic responsibility and openness, and what these terms might mean, could be worked through with ethics board members, computer scientists, the system and my own work and role in the project. Accountability was not accomplished in a single moment, by a single person, but instead was distributed among project members and the ethics board and across ongoing activities, with questions taken back to the project team between meetings and even to be carried forward into future projects after the final ethics board meeting. And the intersection of account-ability and accountability was not simply a bringing together of different registers of account, as if two different forms of account could, for example, sit comfortably together on the same page in a report to the ethics board. The intersecting of account-ability and accountability itself became a productive part of this activity, with questions of accountability challenging the account-able order of the algorithmic system and the more or less orderly sense-making practices of the algorithmic system being used to draw up more precise questions of accountability.

\section{Bearing account-able witness}

In the narrative that opened this paper, algorithms were presented as both consequential and inaccessible, suggesting that holding an algorithmic system to account might prove an important and difficult preparatory aspect of governing algorithms. Drawing on deflationary sensibilities from STS research provided one means to move away from simply accepting the fixed or agential character of algorithms presented in the compelling narrative. However, I suggested these sensibilities also posed problems for bringing the algorithm to account. A single ethnographic snapshot of the algorithm risked appending fixed characteristics and a more or less singular trajectory of development to the algorithm. As an alternative I drew inspiration from ethnomethodological studies of the account-able to look at the ways in which an algorithmic system was expected to, and was involved in the business of, making 
sense of a particular space and how this gave form to the project's ethical aims. Drawing together those with an interest in algorithmic accountability into an ethics board provided the opportunity for concerns of account-ability and accountability to intersect. It seemed possible that the account-able order of the algorithmic system could intersect with a different register of account - the calls for algorithms to be accountable through being more open, transparent, available to be questioned, and even governed. Yet issues that arose in system development and my own entangled practices of witnessing meant that this intersection was never straightforward. What counted as the account-able order of the algorithmic system was continuously subject to change and the ethics board meetings became moments of distributed witnessing where our entanglements of accountability could be worked through.

What, then, can be said about future considerations of algorithms and questions of accountability? First, it seemed useful in this project to engage in detail with the account-able order of the algorithmic system. This replaced a singular ethnographic snapshot of algorithmic activity with an in-depth account of the sense-making activities of the system. Second, however, this approach to account-ability did nothing on its own to address questions of accountability. Intersecting different registers of account through the ethics board was itself a significant project task and required resources, time and effort. Third, the intersection of account-ability and accountability was productive (raising new questions for the project to take on), but also challenging (requiring careful consideration of the means through which different views could be managed). With growing interest in the possibilities of algorithmic accountability, these three areas of activity set out one possible means for future engagement, intersecting the account-able and the accountable and managing the consequences.

\section{Acknowledgements}

I would like to thank the editors and anonymous reviewers for their detailed comments on an earlier version of this paper, to the organizers and participants of the Governing Algorithms event in New York in 2013 for their questions and feedback, and Inga Kroener, Patrick Murphy, Vera Ehrenstein and Sveta Milyaeva for inputs along the way. The research leading to these results has received funding from the European Union Seventh Framework Programme ([FP7/2007-2013] [FP7/2007-2011]) under grant agreement $n^{\circ} 261653$ and 313173. 


\section{References}

Anderson, Bob and Wes Sharrock. 2013. Ethical Algorithms. Available from: http://www.sharrockandanderson.co.uk/wp-content/uploads/2013/03/Ethical-Algorithms.pdf accessed 1st November, 2014.

BBC (2007) Brown apologises for records loss, BBC news on-line, available from: http://news.bbc.co.uk/1/hi/7104945.stm accessed $14^{\text {th }}$ February, 2014

Beer, David. 2009. "Power through the algorithm? Participatory web cultures and the technological unconscious." New Media \& Society 11(6): 985-1002.

Bennett, Colin. 2005. "What happens when you book an airline ticket (revisited): The collection and processing of passenger data post 9/11." In Global Surveillance and Policing, edited by Mark Salter and Elia Zureik, 113-138. Devon: Willan.

Bernal, Paul. 2011. “A Right to Delete?” European Journal of Law and Technology 2(2).

Bijker, Wiebe and John Law, eds. 1992. Shaping Technology/Building Society: Studies in Sociotechnical Change. London: MIT Press.

Bijker, Wiebe, Thomas Hughes and Trevor Pinch. 1989. The Social Construction of Technological Systems: New Directions in the Sociology and History of Technology. London: MIT Press.

Brown, Nick. 2003. "Hope Against Hype - Accountability in Biopasts, Presents and Futures" Science Studies 2: 3-21.

Brown, Nick and Mike Michael. 2003. "A Sociology of Expectations: Retrospecting Prospects and Prospecting Retrospects" Technology Analysis and Strategic Management, 15(1): 3-18

Buscher, Monika, Lisa Wood and Sung-Yeuh Perng. 2013. "Privacy, Security, Liberty" In Proceedings of the 10th International ISCRAM Conference, edited by Tina Comes, Frank Fiedrich, Stephen Fortier and Jutta Geldermann. Baden-Baden, Germany, May 2013, available from: http://www.iscramlive.org/portal/iscram2013proceedings (accessed 24th October, 2014).

Button, Graham and Wes Sharrock. 1998. "The Organizational Accountability of Technological Work.” Social Studies of Science 28 (1): 73-103.

Carrigan, Marylyn and Ahmad Attalla. 2001. "The Myth of the Ethical Consumer: Do ethics matter in purchase behaviour?" Journal of Consumer Marketing 18(7): 560-78.

Cole, Simon. 2009. "A Cautionary Tale About Cautionary Tales About Intervention." Organization 16(1): 121-41.

Collins, Harry. 1987. "Pumps, Rocks and Realities.” Sociological Review 35(4): 819-28. 
Clegg, Stewart, Martin Kornberger and Carl Rhodes. 2007. "Business Ethics as Practice." British Journal of Management 18: 107-122

Davies, Simon. 1996. Big Brother-Britain's Web of Surveillance and the New Technological Order. London: Pan Books.

Diakopoulos, Nick. 2013. Algorithmic Accountability Reporting: On the investigation of black boxes, available from: http://towcenter.org/wp-content/uploads/2014/02/78524_TowCenter-Report-WEB-1.pdf (accessed: $21^{\text {st }}$ October, 2014)

Dourish, Paul. 2004. Where the Action is: The foundations of embodied interactions. Cambridge, MA: MIT Press.

Dubuisson-Quellier, Sophie and Claire Lamine. 2008. "Consumer involvement in fair trade and local food systems: delegation and empowerment regimes." GeoJournal 73:55-65.

Eriksen, Sara. 2002. "Designing for Accountability." Paper presented at NordiCHI, October $19^{\text {th }}-23^{\text {rd }}$.

Fuller, Matthew, ed. 2008. Software Studies. London: MIT Press.

Gad, Christopher and Caspper Bruun-Jensen (2009) "On the Consequences of Post-ANT." Science, Technology and Human Values, 35(1): 55-80.

Garfinkel, Harold. 1967. Studies in Ethnomethodology. Englewood Cliffs, NJ: Prentice Hall.

Goffey, Andrew. 2008. "Algorithm.” In Software Studies, edited by Matthew Fuller, 15-21. London: MIT Press.

Grint, Keith and Steve Woolgar., 1997. The Machine at Work: Technology, Work and Organisation. Cambridge: Polity Press.

Haggerty, Kevin and Richard Ericson. 2000. "The surveillant assemblage.” British Journal of Sociology 51(4): 605-22.

Harawy, Donna. 1997. Modest_Witness@Second_Millennium.FemaleMan_Meets_ OncoMouse: Feminism and Technoscience. London: Routledge.

Heath, Christian and Graham Button. 2002. "Editorial Introduction to Special Issue on Workplace Studies.” British Journal of Sociology, 53(2): 157-61.

Heath, Christian, Paul Luff and Marcus Sanchez Svensson. 2002. "Overseeing Organizations: Configuring action and its environment.” British Journal of Sociology 53(2): 181-201.

Introna, Lucas and Helen Nissenbaum. 2000. Shaping the Web: Why the politics of search engines matters. The Information Society 16(3):1-17.

Introna, Lucas and David Woods. 2004. "Picturing Algorithmic Surveillance: The Politics of Facial Recognition Systems." Surveillance and Society 2(2/3): 177-98. 
James, K. 2013. Open Data? The challenges of algorithmic accountability in big data, available from: http://www.linkedin.com/groups/Open-data-challenges-algorithmicaccountability-3981538.S.5795735833218670594 (accessed $21^{\text {st }}$ October, 2014).

Kitchin, Robert and Martin Dodge. 2011. Code/Space: Software and Everyday Life. London: MIT Press.

Kraemer, Felicitas, Kees van Overveld and Martin Peterson. 2011. Is there an Ethics of Algorithms? Ethics of Information technology 13: 251-60.

LaFollette, Hugh, ed. 2001. Ethics in Practice: An Anthology. Oxford: Blackwells.

Lash, Scott. 2007. "Power After Hegemony" Theory, Culture and Society 24(3): 55-78.

Latour, Bruno. 1990. "Drawing Things Together." In Representation in Scientific Practice, edited by Michael. Lynch and Steve Woolgar, 19-68. Cambridge, MA: MIT.

Law, John. 1991. "Power, Discretion and Strategy." In A Sociology of Monsters - Essays on Power, Technology and Domination, edited by John Law, 165-91. London: Routledge.

Law, John. 1996. "Organising Account Ethics: Ontology and the Mode of Accounting." In Accountability: Power, Ethos and the Technologies of Managing, edited by Rolland Munro and Jan Mouritsen, 283-305. London: International Thomson Business Press.

Law, John. 2004. After Method: Mess in Social Science Research. London: Routledge.

Lynch, Mike. 1993. Scientific Practice and Ordinary Action. Ethnomethodology and Social Studies of Science. Cambridge: Cambridge University Press.

Lynch, Mike, Simon Cole, Ruth McNally and Kathleen Jordan. 2008. Truth Machine. University of Chicago Press: London.

Lyon, David. 2001. Surveillance Society: Monitoring everyday life. Buckingham: Open University Press.

Mackenzie, Adrian. 2006. Cutting Code: Software and Sociality. NY: Peter Lang

Mackenzie, Donald and Judy Wajcman, eds. 1985. The Social Shaping of Technology. Buckingham: Open University Press.

Mayer-Schonberger, Victor. 2009. Delete: The Virtue of Forgetting in the Digital Age. Princeton University Press, NJ, USA.

McCahill, Mike. 2002. The Surveillance Web: The rise of visual surveillance in an English city. Devon: Willan.

Neyland, Daniel. 2006. Privacy, Surveillance and Public Trust. London: Palgrave.

Nicholls, Alex and Nick Lee. 2006. "Purchase decision-making in fair trade and the ethical purchase 'gap': 'is there a fair trade twix?” Journal of Strategic Marketing 14(4): 369-86. 
Norris, Clive and Gary Armstrong. 1999. The Maximum Surveillance Society - The Rise Of CCTV. Oxford: Berg.

Ong, Aihwa and Stephen Collier, eds. 2005. Global Assemblages: Technology, Politics, and Ethics as Anthropological Problems. Oxford: Blackwell.

Rappert, Brian. 2001. "The distribution and resolution of the ambiguities of technologies or why bobby can’t spray.” Social Studies of Science 31(4): 557-92.

Sandvig, Christian, Kevin Hamilton, Karrie Karahalios and Cedric Langbort. 2013.

"ReCentering the Algorithm” Paper presented at 'Governing Algorithms' Conference, New York, $16^{\text {th }}-17^{\text {th }}$ May, 2013. Last accessed $14^{\text {th }}$ February, 2014.

http://governingalgorithms.org/wp-content/uploads/2013/05/4-response-karahalios-et-al.pdf

Slavin, Kevin. 2011. "How algorithms shape our world." Last accessed $14^{\text {th }}$ February, 2014 http://www.ted.com/talks/kevin_slavin_how_algorithms_shape_our_world.html

Spring, Tom. 2011. "How Google, Facebook and Amazon run the internet." Last accessed $14^{\text {th }}$ February, 2014 http://www.pcadvisor.co.uk/features/internet/3304956/how- googlefacebook-andamazonrun-the-internet/

Stalder, Felix and Christine Mayer. 2009. "The Second Index. Search Engines, Personalization and Surveillance." In Deep Search. The Politics of Search beyond Google, edited by Konrad Becker and Felix Stalder, 98-115. New Jersey: Transaction Publishers.

Strathern, Marylyn. 2004. Partial Connections. Oxford: Rowman and Littlefield.

Suchman, Lucy, Randall Trigg and Jeanette Blomberg. 2002. "Working Artefacts: Ethnomethods of the prototype." British Journal of Sociology 53(2): 164-79.

Suchman, Lucy. 2011. “Subject objects.” Feminist Theory 12(2): 119-45.

Taylor, Emmeline. 2010. “I Spy With My Little Eye.” Sociological Review 58(3): 381-405.

Telegraph. 2012. "Digital 'right to be forgotten' to be made EU law." Telegraph on-line, January, $25^{\text {th }}$, accessed: $14^{\text {th }}$ February, 2014.

http://www.telegraph.co.uk/technology/news/9038589/Digital-right-to-be-forgotten-will-bemade-EU-law.html

Thift, Nigel and Shaun French. 2002. "The Automatic Production of Space." Transactions of the Institute of British Geographers 27(3): 309-35.

Van der Ploeg, Irma. 2003. "Biometrics and Privacy: A Note on the Politics of Theorizing Technology." Information, Communication, Society 6(1), 85-104.

Woolgar, Steve. 1991. "Configuring the User: The Case of Usability Trials" In A Sociology of Monsters - Essays on Power, Technology and Domination, edited by John Law, 57-99. London: Routledge. 
Woolgar, Steve. 2002. "Introduction.” In Virtual Society? edited by Steve Woolgar, 1-22. Oxford: Oxford University Press.

\author{
Woolgar, Steve and Daniel Neyland. 2013. Mundane Governance. Oxford: Oxford \\ University Press.
}

\footnotetext{
${ }^{1}$ This is not to suggest that technology operates without consequences, but instead that consequences can be conceived as the product of complex relations, and open to on-going changes that require study (see for example, Law, 1991; Bijker and Law, 1992; Bijker et al., 1989; Woolgar, 1991; 2002; Mackenzie and Wajcman, 1985; Grint and Woolgar, 1997)

${ }^{2}$ This focus on agency as a distributed upshot of network relations is a development of Actor-Network Theory's initial proposition for investigating the agency of things. Such a move has been taken up as one feature of "postANT" approaches (Gad and Bruun-Jensen, 2009)

${ }^{3}$ Deflationary refers to not taking for granted claims made on behalf of a technology and sensibility refers to an empirical move to be continually attuned to the possibility that such claims are being made and thus require deflation.

${ }^{4}$ For more on the ways in which accounts of technology make future times and places available now, see Brown (2003) and Brown and Michael (2003).

${ }^{5}$ Personal and organizational names have been changed to respect requests for anonymity.

${ }^{6}$ This invitation stemmed from my previous work on surveillance systems.

${ }^{7}$ My work would be funded by the project, but my results would not be shaped by the project team.

${ }^{8}$ Existing algorithms would instead be re-purposed.

${ }^{9}$ For example, about privacy, surveillance and excessive visibility (Lyon, 2001; Davies, 1996; Norris and Armstrong, 1999; Bennett, 2005; van der Ploeg, 2003; Taylor, 2010; McCahill, 2002) and concerns raised with algorithmic surveillance (Introna and Woods, 2004).

${ }^{10}$ See for example, Mayer Schonberger (2009), Haggerty and Ericson (2000), BBC (2007), and the new right to be forgotten being discussed as part of the re-drafting of the EU Data Protection Regulation (for a discussion, see Bernal, 2011; Telegraph, 2012).

${ }^{11}$ Waiting until the consequences of a system became clear seemed to mean waiting until most, if not all, design decisions had been made - and these might be design decisions that embodied significant ethical questions. Consequences of design decisions in surveillance are discussed in the "Privacy by Design" literature: https://www.privacyinternational.org/category/free-tags/privacy-design;

http://www.microsoft.com/privacy/bydesign.aspx; http://privacybydesign.ca/

${ }^{12}$ Software studies (see for example, Fuller, 2008; Mackenzie, 2006) is emerging as a field for studying codes, and coded space has become a focus for algorithmic investigation (see Thrift and French, 2002; Kitchin and Dodge, 2011)

${ }^{13}$ One might notice here the subtle transition to "we" through which I have become incorporated into the project.

${ }^{14}$ For example Ong and Collier (2005), Clegg, Kornberger and Rhodes (2007), LaFollette (2001), Carrigan and Attalla (2001), Dubuisson-Quellier and Lamine (2008), Nicholls and Lee (2006).

${ }^{15}$ See Woolgar and Neyland (2013) for an analysis of alternative approaches to accountability.

${ }^{16}$ For more on ethnomethodology and surveillance see Heath, Luff and Svensson (2002)

17 The algorithmic features of the surveillance system could be notable here. In some instances, surveillance technologies such as speed cameras on UK roads might be said to be visible as a reminder to drivers to slow down and other surveillance systems such as CCTV cameras, might be said to be visible in order to similarly remind passers-by of their visibility. In this way accountability relations between the technology and its audience might be an important aspect of its everyday function. The algorithmic components of the surveillance system in this paper would not normally be made apparent, and so making algorithmic surveillance accountable might be looked upon as particularly difficult. However, the extent to which the precise technological set-up of speed cameras and CCTV cameras is made available to drivers and passers-by is questionable and does not seem to form a major component of these systems' accountability (see for example, Neyland, 2006; Woolgar and Neyland, 2013).

${ }^{18}$ Other activities included: a reporting structure through which the computer scientists could report on algorithmic development and testing, an exploration of the possibility that the algorithmic system might produce accounts of its own actions and public demonstrations of the technology. The ethics board is used as the illustrative case of the challenges of intersections between the account-able and accountable.
} 
${ }^{19}$ Design and ethics have a recent history (Buscher, Wood and Perng, 2013, Introna and Nissenbaum, 2000, and Suchman, 2011). However, Anderson and Sharrock (2013) warn against assuming that design decisions set in place an algorithmic ethic.

${ }^{20}$ At least according to computer scientists involved in the project; see below for further complexity on "dropping in" already existing software.

${ }^{21}$ This fits in with a general claim that the vast majority of video-based surveillance footage is never scrutinised (Neyland, 2006)

${ }^{22}$ This decision may appear to narrow the scope of the system under development, but already at this early stage of project discussions, the system was being described as "experimental."

${ }^{23}$ The end users also suggested that these three areas were selected based on accident and crime statistics.

${ }^{24}$ Although of course in an ethnomethodological approach the ethics board meetings are characterised by their own account-able order, here I am presenting a separation between the account-able order of the algorithmic system (how the system participates in making sense of a scene) and the specific questions of accountability posed to that order by the ethics board (posed, for example, through the project's ethical aims).

${ }^{25}$ In March, 2013. Although other months were less frenetic, there were several hundred e-mails during the course of the project on the question of how to get components to talk to each other.

${ }^{26}$ Other questions focused on the route reconstruction system (how many probabilistic routes could be produced through the route reconstruction system with associated metadata while still fulfilling the aim to reduce data?) and deletion system (in testing, the auto-overwrite deletion system frequently left some data untouched, so could the system be said to achieve its ethical aim to reduce the amount of data stored if some orphan files remained?).

${ }^{27}$ Although Collins (1987) briefly uses this term, I use it here to connote a distribution of responsibility and accountability for witnessing the actions taking place in ethics board meetings and subsequent public reports. 